\title{
Low rate of human papillomavirus vaccination among schoolgirls in Lebanon: barriers to vaccination with a focus on mothers' knowledge about available vaccines
}

This article was published in the following Dove Press journal:

Therapeutics and Clinical Risk Management

\section{Maria J Abou El-Ola' \\ Mariam A Rajab ${ }^{2}$ \\ Dania I Abdallah ${ }^{3}$ \\ Ismail A Fawaz ${ }^{4}$ \\ Lyn S Awad ${ }^{5}$ \\ Hani M Tamim 6 \\ Ahmad O lbrahim $^{7}$ \\ Anas M Mugharbil ${ }^{7}$ \\ Rima A Moghnieh ${ }^{8}$}

'Department of Obstetrics and Gynaecology, Makassed General Hospital, Beirut, Lebanon;

2Department of Pediatrics, Makassed General Hospital, Beirut, Lebanon; ${ }^{3}$ Department of Pharmacy, Makassed General Hospital, Beirut, Lebanon; ${ }^{4}$ Department of Internal Medicine, Iklim Health Foundation Hospital, Mazboud, Mount Lebanon, Chouf, Lebanon; ${ }^{5}$ Department of Pharmacy, Makassed General Hospital, Beirut, Lebanon; ${ }^{6}$ Department of Internal Medicine, American University of Beirut, Beirut, Lebanon; ${ }^{7}$ Division of Hematology/Oncology, Department of Internal Medicine, Makassed General Hospital, Beirut, Lebanon; ${ }^{8}$ Division of Infectious Diseases, Department of Internal Medicine, Makassed General Hospital, Beirut, Lebanon

Correspondence: Rima Moghnieh Division of Infectious Diseases, Department of Internal Medicine, Makassed General Hospital, PO Box II-630I, Riad El-Solh, Beirut II 07 22I O, Lebanon

$\mathrm{Tel}+96 \mid 3829363$

Email moghniehrima@gmail.com
Background: Human papillomavirus (HPV) infection is an established predisposing factor of cervical cancer. In this study, we assessed the awareness about genital warts, cervical cancer, and HPV vaccine among mothers having girls who are at the age of primary HPV vaccination attending a group of schools in Lebanon. We also assessed the rate of HPV vaccination among these girls and the barriers to vaccination in this community.

Subjects and methods: This is a cross-sectional, school-based survey. A 23-item, selfadministered, anonymous, pretested, structured questionnaire with closed-ended questions was used to obtain data. The questionnaire was sent to the mothers through their student girls, and they were asked to return it within a week. Data were analyzed using the Statistical Package for Social Sciences version 21.0. Bivariate analysis was performed using the chi-square test to compare categorical variables, whereas continuous variables were compared using the Student's $t$-test. Fisher's exact test was used when chi-square test could not be employed.

Results: The response rate in our survey was 39.4\%. Among the responders, the rate of awareness about HPV infection was $34 \%$, where $72 \%$ of the mothers had heard about cervical cancer, and $34 \%$ knew that a vaccine is available to prevent cervical cancer. HPV vaccination uptake rate was $2.5 \%$. This lack of vaccination was primarily attributed to the low rate of mothers' awareness about the vaccine (34\%). Factors significantly affecting awareness about the vaccine were the mothers' marital age, nationality, level of education, employment, and family income. Barriers to HPV vaccination, other than awareness, were uncertainty about safety or efficacy of the vaccine, conservative ideas of mothers regarding their girls' future sexual life, and relatively high price of the vaccine.

Conclusion: Vaccine uptake is low among eligible girls attending this group of schools. The barriers to vaccination are multiple; the most important one is the mothers' lack of knowledge about HPV, cervical cancer, and the modes of prevention. Awareness campaigns along with a multimodal strategy that targets the identified barriers would be recommended to achieve higher rates of HPV vaccination.

Keywords: awareness, barriers, cervical cancer, human papillomavirus, knowledge, Lebanon, mothers, schools, vaccine

\section{Introduction}

Globally, cervical cancer is the fourth most commonly diagnosed cancer and fourth leading cause of cancer-related deaths among females. ${ }^{1}$ Human papillomavirus (HPV) is a well-established risk factor for cervical cancer. ${ }^{2}$ 
In Lebanon, about $2.2 \%$ of the women in the general population are estimated to harbor cervical HPV infection at a certain time. The prevalence of HPV reached $4.9 \%$ among a cohort of Lebanese women aged $18-76$ years $(n=1,026)$ seeking routine gynecological care at a tertiary care center. ${ }^{3,4}$ Cervical cancer ranks as the 11th most frequent cancer among Lebanese women and the 6th most common cancer in women aged 15-44 years. ${ }^{5}$ About 113 new cases are annually diagnosed. ${ }^{5}$ With respect to mortality, 42 patients die from the disease annually, ranking it the 12th leading cause of female cancer deaths. ${ }^{5}$

In 2009, the World Health Organization (WHO) recommended HPV vaccination in countries where cervical cancer has become a public health priority and the introduction of HPV vaccine is feasible and financially sustainable. ${ }^{6}$ The primary target group in most of the countries recommended to promulgate HPV vaccination is young adolescent girls in the age group of 9-14 years. ${ }^{7}$ However, this range can be extended according to the estimated age of the first sexual encounter. ${ }^{7}$

Two HPV vaccines are currently available in Lebanon, Gardasil $^{\circledR}$ (Merck \& Co., Whitehouse Station, NJ, USA) and Cervarix ${ }^{\circledR}$ (GlaxoSmithKline Biologicals, Rixensart, Belgium). Both vaccines are prescribed and the choice depends on the physician and patient/guardian's preferences. In Lebanon, so far, there is no national adult vaccination program, and HPV vaccination is not endorsed by third-party payers. ${ }^{8}$ The decision for HPV vaccination relies entirely on the young woman and/or her family.

In order to evaluate the current situation of HPV vaccination uptake in Lebanon, we conducted a survey among mothers or guardians having schoolgirls at an age of primary HPV vaccination. In this study, we assessed the mothers'/ guardians' awareness about genital warts, cervical cancer, and HPV vaccine. We also determined the rate of HPV vaccination among eligible schoolgirls and the possible barriers to this vaccination.

\section{Methods}

This is a cross-sectional survey conducted in a group of schools in Beirut, Lebanon from September 2016 to February 2017. Responders to our questionnaire were mothers or guardians of schoolgirls aged 9-18 years. In most countries, the primary target group for HPV vaccine is girls between 9 and 14 years. ${ }^{7}$ However, the WHO still recommends a three-dose schedule for those aged $\geq 15$ years, ${ }^{7}$ taking into consideration the late sexual debut in certain conservative societies like ours. ${ }^{9}$ Accordingly, in our society, girls aged 9-18 years still belong to the primary target group for HPV vaccination. If the biological mother was dead or unreachable, the guardian in charge of the schoolgirl was requested to answer the questionnaire. If the guardian was not a woman, he was excluded from the study to avoid guardian gender bias. In this study, we used the terms "mother" and "guardian" interchangeably. For each vaccine-eligible schoolgirl, a corresponding mother was included in the mothers' group. For example, if two girls were sisters, their mother was counted twice accordingly.

Investigators belonged to the Internal Medicine, Obstetrics/ Gynaecology, Paediatrics, and Pharmacy departments of Makassed General Hospital (MGH), a tertiary-care university hospital in Beirut, Lebanon. Lebanon is a relatively small country with a heterogeneous mixture of religions. This study was performed in 13 schools, most of which belonged to the Makassed Islamic Philanthropic Association. Because of the insufficient number of questionnaires completed by Makassed schools, we extended the survey to areas of geographical proximity and socioeconomic/religious equivalence, including Sidon city in the South Governorate of Lebanon and Iqlim El-Kharroub, situated in the Mount Lebanon Governorate.

A 23-item, self-administered, anonymous, pretested, structured questionnaire with closed-ended questions was used to obtain data. The creation of our questionnaire was based on previously validated and reliable tools from the literature, including the Cervical-Cancer-KnowledgePrevention-64 (CCKP-64) questionnaire, ${ }^{10}$ adapted from the European Organization for Research and Treatment of Cancer (EORTC) Quality of Life Group guidelines for questionnaire development ${ }^{11}$ and the Creencias-PapanicolaouCancer-28 (CPC-28) questionnaire, which used the Health Belief Model (HBM) as a framework. ${ }^{10}$ We also adapted our questions from previous studies. ${ }^{13-18}$

Our tool was written in English and was approved by a multidisciplinary group including two infectious-diseases specialists (RM and IF), a gynecologist (MA), a pediatrician (MR), and two pharmacists (LA and DA). It was then translated to Arabic to be pilot tested on a convenience sample of 20 teachers aged between 25 and 40 years from one of the Makassed schools in Beirut to ensure clarity, appropriate wording, and ease of administration. Data of the pilot test were not included in this study.

The questionnaires along with the informed consent form were given to school administration officers who distributed 
them to the girl students so that they take it home to their mothers. The mothers were requested to return the completed questionnaire via their child back to the school administration officers within 7 days.

Our questionnaire targeted the following information:

1. The sociodemographic and socioeconomic features of mothers and their families.

2. The awareness/knowledge of the mother about genital warts, cervical cancer, HPV mode of transmission, and HPV vaccine (the questions related to awareness were asked if the person has ever heard of the issue).

3. Risk factors stemming from lack of this awareness.

4. HPV vaccination status of corresponding girls.

5. Barriers to HPV vaccination among the eligible girls possibly related to the following:

a. The mother's perception of her girl's and her future son-in-law's sexual/couple life.

b. Lack of knowledge about available HPV vaccine.

c. Concerns about HPV vaccine's safety and efficacy.

d. Any source of information about HPV vaccine, whether from pediatricians, obstetricians, friends, family, media, etc.

e. The price of the vaccine.

The responses were categorized and compared as follows:

1. Answers of mothers who were aware about the HPV vaccine versus those who were not aware about the vaccine.

2. Answers of mothers with vaccinated girls versus those with unvaccinated girls.

The socioeconomic classification in this survey was adopted from the 2013 World Bank analysis of the Quality Life Index. ${ }^{19}$ Ranking was estimated as follows:

1. Below poverty line: a monthly salary $\leq 210$ USD

2. Moderate middle class: a monthly salary of 750 USD

3. Upper middle class: a monthly salary between 1,250 USD and 2,250 USD

4. Highest upper class: a monthly salary $\geq 2,500$ USD Yearly school fees were grouped as follows:

1. Low fee: below 2,000 USD.

2. Intermediate fee: between 2,000 USD and 4,000 USD.

3. High fee: above 4,700 USD.

\section{Ethical approval}

Makassed General Hospital Institutional Review Board committee and The Lebanese Ministry of Education and Higher Education approved this study.

\section{Informed consent}

Consent forms written in Arabic were sent to mothers to be signed upon participation. During the data collection phase, names were omitted and only initials were included. At a later stage, a number was assigned to each of our participants to safeguard participant privacy.

\section{Statistical analysis}

Based on the convenience, the sample size set for this study was 3,025. Data were analyzed using the Statistical Package for Social Sciences, version 21.0 (IBM Corporation, Armonk, NY, USA). A $p$-value of $<0.05$ was accepted as statistically significant. Categorical variables were presented as number and percent, whereas continuous variables were presented as mean and standard deviation. Univariate analysis was performed using the chi-square test for comparing categorical variables, whereas continuous variables were compared using Student's $t$-test. Fisher's exact test was used to determine statistical significance in case of a small sample size when chi-square test could not be employed.

\section{Results}

\section{Response rate of the questionnaire}

A total of 3,025 questionnaires were distributed. The total response rate was $39.4 \%$ (1,193/3,025 forms). The majority of the questionnaires were distributed to intermediatefee schools $(1,509 / 3,025$ forms, 49.9\%), followed by low-fee schools (860/3,025 forms, 28.4\%), and then by high-fee schools $(21.7 \%)$. Responders were mostly from intermediate-fee schools (661/1,193 forms, 55.4\%) followed by low-fee schools $(458 / 1,193,38.4 \%)$, and least from highfee schools $(74 / 1,193,6.2 \%)$.

\section{General information pertinent to participating mothers}

The mean age of the responders was around $43 \pm 6$ years with a mean marital age of $22 \pm 4$ years. Most of them were Lebanese nationals (88\%), and over 95\% were Muslims. With respect to their education, $40 \%$ held a high school degree and $28 \%$ had a university degree. Only $23.4 \%$ of the participants were working mothers, of whom only $16.5 \%$ worked in the health care sector. With regard to the family income, $24 \%$ of the participants belonged to the moderate middle class, with a monthly income between 450 and 1,000 USD, followed by $21 \%$ of the upper middle class, with a monthly income between 1,000 and 2,000 USD (Table 1). 
Table I Demographic and socioeconomic characteristics of participating mothers and their awareness about genital warts, cervical cancer, and HPV vaccine

\begin{tabular}{|c|c|}
\hline Parameters & $\begin{array}{l}\text { Number of responders (\%) } \\
(\mathrm{N}=I, 193)\end{array}$ \\
\hline Mother's age, years (mean \pm SD) & $42.6( \pm 5.80)$ \\
\hline Mother's marital age, years (mean $\pm S D$ ) & $21.7( \pm 4.25)$ \\
\hline \multicolumn{2}{|c|}{ Number of children } \\
\hline I & $58(4.9)$ \\
\hline 2 & $231(19.4)$ \\
\hline 3 & $430(36)$ \\
\hline 4 & $301(25.2)$ \\
\hline 5 & $119(10)$ \\
\hline$>5$ & $54(4.5)$ \\
\hline \multicolumn{2}{|l|}{ Nationality } \\
\hline Lebanese & I,05I (88.I) \\
\hline Palestinian & $52(4.4)$ \\
\hline Syrian & $77(6.5)$ \\
\hline Others & $13(1.1)$ \\
\hline \multicolumn{2}{|l|}{ Educational level } \\
\hline Below elementary & $90(7.6)$ \\
\hline Middle school & $330(27.7)$ \\
\hline High school & $404(33.9)$ \\
\hline University degree & $337(28.3)$ \\
\hline Higher education & $31(2.6)$ \\
\hline \multicolumn{2}{|l|}{ Religion } \\
\hline Muslim & $\mathrm{I}, 142(95.7)$ \\
\hline Christian & $48(4)$ \\
\hline Secularism & $3(0.3)$ \\
\hline \multicolumn{2}{|l|}{ Working mother } \\
\hline Yes & $279(23.4)$ \\
\hline No & $912(76.4)$ \\
\hline Unknown & $2(0.2)$ \\
\hline \multicolumn{2}{|l|}{ Work status } \\
\hline Health care worker & $46(3.9)$ \\
\hline Non-health care worker & $204(17.9)$ \\
\hline Unknown & $29(2.4)$ \\
\hline \multicolumn{2}{|l|}{ Monthly family income (USD) } \\
\hline$<450$ & 139 (II.7) \\
\hline $450-1,000$ & $289(24.2)$ \\
\hline $1,000-2,000$ & $253(2 \mid .2)$ \\
\hline$>2,000$ & $185(15.5)$ \\
\hline Unknown & $327(27.4)$ \\
\hline Awareness about genital warts & $310(26)$ \\
\hline Awareness about cervical cancer & 858 (7I.9) \\
\hline Awareness about HPV vaccine & $408(34.2)$ \\
\hline
\end{tabular}

\section{Mothers' awareness about genital warts, cervical cancer, and HPV vaccine}

Twenty-six percent of the mothers knew about genital warts, and $71.9 \%$ had already heard of cervical cancer and its complications. Only $34.2 \%$ of mothers who filled out the questionnaire knew about the vaccine (Table 1).

\section{Factors affecting HPV vaccine awareness}

The rate of awareness regarding HPV vaccine in this study was found to be around $34.2 \%$ (Table 1). It was directly affected by the mothers' marital age $(p<0.0001)$, level of education $(p<0.0001)$, and nationality as being Lebanese $(p<0.0001)$ (Table 2). In addition, working mothers were more likely to have heard of the vaccine compared to nonworking mothers $(52.7 \%$ vs $47.3 \%, p<0.0001)$, specifically those employed in the health care sector $(89.1 \%$ vs $10.9 \%$, $p<0.0001)$. Moreover, mothers belonging to families with incomes above 2,000 USD were more likely to be aware about HPV vaccine than those belonging to families with lower incomes $(p<0.0001)$ (Table 2). Twenty-two percent of the mothers consulted a pediatrician who offered the HPV vaccine to their girls, and $97.7 \%$ of this subgroup were aware about the vaccine (Table 2).

\section{HPV vaccination rate}

The vaccination rate of HPV in this study was only $2.5 \%$ of the vaccine-eligible category. Even though the rate of vaccination was statistically higher among those who were aware of both the cancer and the vaccine compared to those who were not, the rate of vaccination among those who knew did not exceed 7.4\% $(p<0.0001)$ (Table 3$)$.

\section{Vaccine-related barriers}

Among mothers of non-vaccinated girls, $14.4 \%$ attributed lack of vaccination to high cost, $2.9 \%$ of them did not vaccinate their girls because they thought the vaccine was ineffective, and $11.7 \%$ did not vaccinate because they were concerned about its safety (Table 3 ).

\section{Mothers' perception of their girls' sexual/ couple life}

With respect to the mothers' perception about their girls' sexual activity and couple life (Table 3 ), $87.8 \%$ of the mothers $(939 / 1,070)$ expected their girls to be married between the ages of 20 and 25 years. The rate of HPV vaccination was directly related with the expected age of marriage $(p=0.042)$. Mothers who expected their girls to be married at a younger age were less likely to vaccinate them. Three-fourths of the responders (875/1,168 participants) believed that the future young couple would always be monogamous; only $0.9 \%$ (10/1,175 participants) of the responders expected that their girls might have premarital sex, and $18.2 \%$ expected that the future son-in-law would possibly have had a premarital sexual experience. Despite the very few who had a permissive view of the sexual life of the young couple, the rate of 
Table 2 Comparison between mothers who were aware about HPV vaccine and those who were not in relation to their demographic features, socioeconomic status, and knowledge about cervical cancer

\begin{tabular}{|c|c|c|c|c|c|}
\hline Parameters & $\begin{array}{l}\text { Total } \\
\text { responders }\end{array}$ & $\begin{array}{l}\text { Number of } \\
\text { mothers aware of } \\
\text { the HPV vaccine }\end{array}$ & $\begin{array}{l}\text { Number of mothers } \\
\text { who were not aware } \\
\text { of the HPV vaccine }\end{array}$ & $\begin{array}{l}\text { Chi-square } \\
\text { value }\end{array}$ & $P$-value \\
\hline Mother's age (years) & $\mathrm{I}, 193$ & $408(34.2 \%)$ & $785(65.8 \%)$ & & \\
\hline$<40$ & $352(29.5 \%)$ & $1 \mathrm{II}(31.5 \%)$ & $24 I(67.5 \%)$ & 1.6 & 0.453 \\
\hline $40-50$ & 735 (61.6\%) & $260(35.4 \%)$ & 475 (64.6\%) & & \\
\hline$>50$ & $106(8.9 \%)$ & 37 (34.9\%) & $69(65.1 \%)$ & & \\
\hline Mother's marital age (years) & 1,193 & 408 (34.2\%) & 785 (65.8\%) & & \\
\hline$\leq 18$ & $298(25 \%)$ & $65(21.8 \%)$ & $233(77.2 \%)$ & 35.9 & $<0.000$ I \\
\hline $19-23$ & $516(43.3 \%)$ & 177 (34.3\%) & 339 (65.7\%) & & \\
\hline $24-28$ & $304(25.5 \%)$ & $132(43.4 \%)$ & $172(56.6 \%)$ & & \\
\hline$\geq 29$ & $75(6.3 \%)$ & $34(45.3 \%)$ & $4 \mathrm{I}(54.7 \%)$ & & \\
\hline Mother's nationality & 1,193 & $408(34.2 \%)$ & 785 (65.8\%) & & \\
\hline Lebanese & I,05I (88.I\%) & 388 (36.9\%) & $663(63.1 \%)$ & 31.6 & $<0.000$ I \\
\hline Syrian & $52(4.4 \%)$ & $3(5.8 \%)$ & $49(94.2 \%)$ & & \\
\hline Palestinian & 77 (6.5\%) & $15(19.5 \%)$ & $62(79.5 \%)$ & & \\
\hline Other & $13(1.1 \%)$ & $2(15.4 \%)$ & II (84.6\%) & & \\
\hline Mother's educational level & 1,192 & 408 (34.2\%) & $784(65.8 \%)$ & & \\
\hline Below elementary & $90(7.6 \%)$ & $8(8.9 \%)$ & $82(91.1 \%)$ & 68.9 & $<0.000$ I \\
\hline Middle school & $330(27.7 \%)$ & $87(26.4 \%)$ & $243(73.6 \%)$ & & \\
\hline High school & $404(33.9 \%)$ & $136(33.7 \%)$ & $268(65.3 \%)$ & & \\
\hline University & $337(28.3 \%)$ & $158(46.9 \%)$ & $179(53.1 \%)$ & & \\
\hline Higher education & $31(2.6 \%)$ & $19(61.3 \%)$ & $12(38.7 \%)$ & & \\
\hline Working mother & 1,191 & 407 (34.2\%) & $784(65.8 \%)$ & & \\
\hline Yes & $279(23.4 \%)$ & 147 (52.7\%) & $132(47.3 \%)$ & 55.5 & $<0.000$ I \\
\hline No & $912(76.6 \%)$ & $260(28.5 \%)$ & $652(71.5 \%)$ & & \\
\hline Mother's work sector & 250 & $133(53.2 \%)$ & $117(46.8 \%)$ & & \\
\hline Health care worker & $46(18.4 \%)$ & $4 \mathrm{l}(89.1 \%)$ & $5(10.9 \%)$ & 29.2 & $<0.000$ I \\
\hline Non-health care worker & $204(81.6 \%)$ & $92(45.1 \%)$ & 112 (54.9\%) & & \\
\hline Monthly family income & 866 & $296(34.2 \%)$ & $570(65.8 \%)$ & & \\
\hline$<450$ USD & $139(16.1 \%)$ & $24(17.3 \%)$ & 115 (82.7\%) & 57.3 & $<0.000$ I \\
\hline $450-1,000$ USD & $289(33.4 \%)$ & $77(26.6 \%)$ & $212(72.4 \%)$ & & \\
\hline $\mathrm{I}, 000-2,000$ USD & $253(29.2 \%)$ & $96(37.9 \%)$ & $157(62.1 \%)$ & & \\
\hline$>2,000$ USD & $185(21.4 \%)$ & $99(53.5 \%)$ & $86(46.5 \%)$ & & \\
\hline Knowledge about cervical cancer & 1,192 & 408 (34.0\%) & $784(66.0 \%)$ & & \\
\hline Yes & $858(72 \%)$ & 404 (47.1\%) & $454(52.9 \%)$ & $*$ & $<0.000$ I \\
\hline No & $334(28 \%)$ & $4(1.2 \%)$ & $330(98.8 \%)$ & & \\
\hline Pediatrician offering HPV vaccine & 1,193 & 408 (34.2\%) & $785(65.8 \%)$ & & \\
\hline Yes & 264 (22.1\%) & $258(97.7 \%)$ & $6(2.3 \%)$ & 608.0 & $<0.000$ I \\
\hline No & $929(77.9 \%)$ & $150(16.1 \%)$ & 779 (83.9\%) & & \\
\hline
\end{tabular}

Note: *Fisher's exact test was used.

Abbreviations: HPV, human papillomavirus; USD, US dollars.

vaccination was low and was not statistically different from those who exercised a conservative, puritanical attitude. In addition, $26 \%$ of the total participants were aware of the sexual transmission of HPV.

\section{Source of information about disease and vaccine}

Sixty-six percent of mothers were informed about cervical cancer and HPV vaccine by their obstetricians, but only $3.2 \%$ of the girls got vaccinated. However, when the source of information came from pediatricians, the vaccination rate was higher (13.6\%) than other sources such as from obstetricians (3.2\%). The vaccination rate was nil when the source of information was the social media, educational audio-visual programs, or family $(p<0.0001)$ (Table 3$)$.

\section{Discussion}

\section{Choice of the interviewed population}

The questioned population about HPV disease and the vaccine varies from one study to the other to include young 
Table 3 Comparison between mothers who vaccinated their girls and those who did not with respect to different aspects of the girls' sexual life and the mothers' knowledge about cervical cancer, HPV, and the vaccine

\begin{tabular}{|c|c|c|c|c|c|}
\hline Parameters & $\begin{array}{l}\text { Total } \\
\text { responders, } \\
\text { n (\%) }\end{array}$ & $\begin{array}{l}\text { Number of mothers } \\
\text { with vaccinated } \\
\text { girls, } \mathbf{n}(\%)\end{array}$ & $\begin{array}{l}\text { Number of mothers } \\
\text { with non-vaccinated } \\
\text { girls, } \mathbf{n}(\%)\end{array}$ & $\begin{array}{l}\text { Chi-square } \\
\text { value }\end{array}$ & $P$-value \\
\hline The girl received all childhood vaccines & 1,193 & $30(2.5)$ & $\mathrm{I}, 163(97.5)$ & & \\
\hline Yes & $1,029(86.3)$ & $28(2.7)$ & $\mathrm{I}, 00 \mathrm{I}(97.3)$ & * & 0.417 \\
\hline Girls' expected age of marriage, years & $\mathrm{I}, 070$ & $27(2.5)$ & $\mathrm{I}, 043(97.5)$ & & \\
\hline$<20$ & $42(3.9)$ & 0 & $42(100)$ & 8.2 & 0.042 \\
\hline $20-25$ & $939(87.8)$ & $21(2.2)$ & $918(97.8)$ & & \\
\hline $26-30$ & $87(8.1)$ & $6(6.9)$ & $81(92.1)$ & & \\
\hline$>30$ & $2(0.2)$ & 0 & $2(100)$ & & \\
\hline A girl might be sexually active before marriage & 1,175 & $29(2.5)$ & $\mathrm{I}, \mathrm{I} 46(97.5)$ & & \\
\hline Yes & $10(0.9)$ & 0 & $10(100)$ & * & 1.00 \\
\hline No & I,I 65 (99.I) & $29(2.5)$ & $1,136(97.5)$ & & \\
\hline \multicolumn{6}{|l|}{ premarital sexual experience } \\
\hline Yes & $208(18.2)$ & $5(2.4)$ & $203(97.6)$ & 4.7 & 0.095 \\
\hline No & $932(81.8)$ & $22(2.4)$ & $910(97.6)$ & & \\
\hline Belief that marriage is always monogamous & 1,168 & $30(2.6)$ & I, $138(97.4)$ & & \\
\hline \multicolumn{6}{|l|}{ from both partners } \\
\hline Yes & 875 (74.9) & $23(2.6)$ & $852(97.4)$ & 0.2 & 0.913 \\
\hline No & $293(25.1)$ & $7(2.4)$ & $286(97.6)$ & & \\
\hline Knowledge about HPV vaccine & 1,193 & $30(2.5)$ & $\mathrm{I}, 163(97.5)$ & & \\
\hline Yes & $408(34.2)$ & $30(7.4)$ & $378(92.6)$ & * & $<0.0001$ \\
\hline No & $785(65.8)$ & 0 & $785(100.0)$ & & \\
\hline Knowledge about cervical cancer & 1,192 & $30(2.6)$ & $1,162(97.4)$ & & \\
\hline Yes & $858(72)$ & $30(3.5)$ & $828(96.5)$ & * & $<0.0001$ \\
\hline No & $334(28)$ & 0 & $334(100)$ & & \\
\hline Knowledge about warts & 1,193 & $30(2.5)$ & $1,163(97.5)$ & & \\
\hline Yes & $310(26)$ & $17(5.5)$ & $293(94.5)$ & 15.1 & $<0.0001$ \\
\hline No & $883(74)$ & $13(1.5)$ & $870(98.5)$ & & \\
\hline Knowledge about the sexual transmission & 1,193 & $30(2.5)$ & I, $163(97.5)$ & & \\
\hline \multicolumn{6}{|l|}{ of HPV } \\
\hline Yes & $310(26)$ & $17(5.5)$ & $293(94.5)$ & 15.0 & $<0.0001$ \\
\hline No & $883(74)$ & $13(1.5)$ & $870(98.5)$ & & \\
\hline Family history of cervical cancer & 1,193 & $30(2.5)$ & $1,163(97.5)$ & & \\
\hline Yes & $80(6.7)$ & 0 & $80(100)$ & * & 0.257 \\
\hline No & $1,113(93.3)$ & $30(2.7)$ & $1,083(97.3)$ & & \\
\hline Source of information about cervical cancer & 857 & $30(3.5)$ & $827(96.5)$ & & \\
\hline Obstetrician & $569(66.4)$ & $18(3.2)$ & $551(96.8)$ & 34.0 & $<0.0001$ \\
\hline Pediatrician & $88(10.3)$ & $12(13.6)$ & $76(86.4)$ & & \\
\hline $\begin{array}{l}\text { Social media and educational audio-visual } \\
\text { programs }\end{array}$ & $150(17.5)$ & 0 & $150(100)$ & & \\
\hline Family history & $37(4.3)$ & 0 & $37(100)$ & & \\
\hline Other & $13(1.5)$ & 0 & $13(100)$ & & \\
\hline Pediatrician offering HPV vaccine & 1,193 & $30(2.5)$ & $1,163(97.5)$ & & \\
\hline Yes & $264(22.1)$ & $28(10.6)$ & $236(89.4)$ & * & $<0.000$ I \\
\hline No & 929 (77.9) & $2(0.2)$ & $927(99.8)$ & & \\
\hline Belief that the vaccine is not safe ${ }^{a}$ & 1,163 & NA & $1,163(100)$ & & \\
\hline Yes & $136(11.7)$ & NA & $136(100)$ & - & - \\
\hline No & $1,027(88.3)$ & NA & $1,027(100)$ & & \\
\hline Belief that the vaccine is not effective ${ }^{a}$ & 1,163 & NA & $1,163(100)$ & & \\
\hline Yes & $34(2.9)$ & NA & $34(100)$ & - & - \\
\hline No & I,I 29 (97.I) & NA & $1,129(100)$ & & \\
\hline Belief that the vaccine is unaffordable ${ }^{a}$ & 1,163 & NA & $1,163(100)$ & & \\
\hline Yes & $168(14.4)$ & NA & $168(100)$ & - & - \\
\hline No & $995(85.6)$ & NA & $995(100)$ & & \\
\hline Monthly family income (USD) & 866 & $16(1.8)$ & $850(98.2)$ & & \\
\hline$<450$ & $139(16.1)$ & I $(0.7)$ & I 38 (99.3) & 1.2 & 0.757 \\
\hline $450-1,000$ & $289(33.4)$ & $6(2.1)$ & $283(97.9)$ & & \\
\hline $1,000-2,000$ & $253(29.2)$ & $5(2)$ & $248(98)$ & & \\
\hline$>2,000$ & $185(2 \mid .4)$ & $4(2.2)$ & $18 \mid(97.8)$ & & \\
\hline
\end{tabular}

Notes: *Fisher's exact test was used; aThese questions were asked only to mothers of non-vaccinated girls. Abbreviations: NA, not available; USD, US dollars. 
female adolescents, young women, and mothers. ${ }^{9,20-23}$ In our study, we chose to have the mothers answer the questionnaire, because in Lebanon, the medical decisions for this age group are mostly taken by the parents, especially, the mothers.

\section{Response rate}

In this study, the response rate of mothers who responded to our questionnaire was $39.4 \%$, with no direct interference from the researchers or the schools' teachers/administrators. Similar to our findings, in a cross-sectional, internet-based survey assessing behavioral perceptions of catch-up HPV vaccination among female college students attending a private academic institution in Lebanon, the reported response rate was found to be $42 \%{ }^{8}$ This is usually what one would expect of a response rate in a non-face-to-face setting. ${ }^{24}$ Reviewing response rates to paper-based and online-based surveys concluded that non-face-to-face surveys of both types generally yielded low response rates not exceeding 33.3\%. ${ }^{24}$ Unlikely, face-to-face surveys could generate much higher response rates that may reach up to $80 \%$ due to the direct interaction between the investigators and the interviewed population $\%{ }^{24}$

\section{Mothers' awareness about cervical cancer, its relation to HPV, and the vaccine}

In our population, $71.9 \%$ of the mothers were aware about cervical cancer. Knowledge about cervical cancer significantly affected both the rate of vaccination $(3.5 \%$ vs $0 \%)$ and awareness about vaccine $(47.1 \%$ vs $1.2 \%)(p<0.0001)$. Lack of knowledge about vaccines and vaccine-preventable diseases in key role players, such as parents, is a major challenge that hinders optimal vaccine uptake by adolescents. A Moroccan study, assessing awareness of HPV and its vaccine among parents with at least one unmarried daughter with an age of 26 years and less showed that none of the interviewed parents had their daughter(s) vaccinated. ${ }^{21}$ The Moroccan experience confirms this idea when $97 \%$ of the parents did not have sufficient information about the vaccine, which probably explains the lack of vaccination among the concerned group. ${ }^{21}$ Consequently, awareness campaigns about the disease and its prevention targeting mothers of girls who are eligible for the vaccine would be recommended to improve vaccine uptake among HPV vaccine-eligible girls.

\section{Factors affecting mothers' awareness about HPV vaccine}

In our series, the awareness about HPV vaccine reached $34.2 \%$. We observed that as the mother's marital age increased, so did her awareness about the vaccine $(p<0.0001)$. Furthermore, working mothers, specifically in the health care sector and those who belonged to families with a high income positively affected awareness $(p<0.0001)$. Being a health care employee was a factor for improved awareness based on results from a cross-sectional Iraqi study evaluating the knowledge about HPV and cervical cancer among female college students and female health care workers. ${ }^{25}$ Thus, we conclude that awareness efforts in Lebanon, and similarly in Iraq, are missing a sector of housewives and mothers who are not in the workforce. Consequently, we recommend targeting this group in any awareness campaign.

\section{Rate of HPV vaccine uptake}

The rate of primary HPV vaccination among schoolgirls in this study was $2.5 \%$. A higher rate of HPV vaccination (17\%) was observed in the formerly mentioned Lebanese survey involving college students attending an academic institution with expensive fees, which reflects a difference in vaccine uptake in the same country among different socioeconomic classes. ${ }^{9}$ However, similar to our results, a low vaccination rate $(1.4 \%)$ was observed among girls aged 9-24 years attending the adolescent unit at a tertiary care medical center in Ankara, Turkey. ${ }^{20}$

\section{Factors hindering HPV vaccination}

In this study, we identified several potential barriers to HPV vaccination. They were as follows: the mothers' conservatism toward their girls' sexual life, lack of awareness about the vaccine, concerns about the vaccine's safety and to a lesser extent its efficacy, the source of information about cervical cancer and the vaccine, in addition to the relatively high price of the vaccine.

First, most of the chosen schools belonged to an Islamic organization, known to be conservative but not extremist. The majority of our mothers denied the possibility of their girl's or their future son-in-law's having premarital sexual affairs. In many societies, cultural and conservative religious norms largely affect HPV vaccine acceptability. This has been proven in a British cross-sectional study that evaluated predictors of interest in HPV vaccine among female adolescents (16-19 years). ${ }^{22}$ Their results have shown that religion remained a significant factor affecting acceptability, with girls from Muslim or Hindu/Sikh backgrounds less likely to accept vaccination. ${ }^{22}$ In such conservative communities, parents were concerned that these vaccines could represent "a license to have premarital sex." In parallel, Gordon et al qualitatively assessed attitudes toward HPV vaccination in the British Jewish community. ${ }^{23}$ Mothers were convinced 
that their girls' conservative lifestyle protected them from acquiring cervical cancer, and this had played a role in their decision to decline vaccination. ${ }^{23}$ Instead, in the aforementioned Lebanese study, when college students who belonged to a less conservative social class were questioned about their sexual life, $62 \%$ believed that they had a good chance of contracting HPV later in life, ${ }^{9}$ and this group had a higher rate of HPV vaccination than our group of students. Thus, belonging to a conservative ethnic, religious group, or social class could be a barrier to HPV vaccination. Therefore, this fact should be taken into consideration when planning a vaccination campaign in such strict societies, where the message should shed light on the complexity of sexual life in spite of social or religious beliefs.

Second, although awareness about the disease and its vaccine did make a statistically significant difference in the rate of vaccine uptake in our studied group $(p<0.0001)$, it was very low among the proportion that knew about the vaccine $(7.4 \%)$ or the disease $(3.5 \%)$.

Third, our results showed that $11.7 \%$ of the mothers with non-vaccinated girls were concerned about its adverse effects and $2.9 \%$ of the same group thought that it was ineffective. In the Moroccan cohort, ${ }^{21}$ parents were equally concerned about the vaccine's efficacy and safety: $25 \%$ thought that the vaccine did not provide full protection, $50 \%$ thought that the vaccine was new and they preferred to wait a while, and $51 \%$ were concerned about its side effects. Accordingly, data confirming the safety and efficacy of HPV vaccine must be included in awareness campaigns.

Fourth, our findings showed that the source providing mothers with information about HPV, cervical cancer, and the link between the two from one side, in addition to the method of prevention through vaccination from another side significantly contributed to the low rate of vaccination among their girls. Pediatricians' messages to mothers concerning cervical cancer and HPV vaccine led to a significantly higher rate of vaccine uptake $(13.6 \%)$ in comparison with obstetricians' messages $(3.2 \%)(p<0.0001)$. This might be due to the common practice of childhood vaccination that usually takes place in pediatric clinics and not in obstetricians' clinics. Furthermore, the focus of the pediatricians' visit is normally the girl. While, the focus of the obstetricians' visit is generally the mother, and the girl remains a virtual patient. Studies in human communication have shown that how health messages that are framed plays a major role in response and advice uptake. ${ }^{26}$ According to a systematic review of the literature by Kessels et al studying factors associated with HPV vaccine uptake in teenage girls, the provider-initiated model, represented by careful and factual advice on vaccination to adolescents and their parents by health care providers, will result in more willingness to be vaccinated in developing countries. ${ }^{27}$

Finally, the price of the vaccine was another major constraint. In Lebanon, the government subsidizes most of the childhood vaccines included in the national vaccination program; adolescent and adult vaccines, however, are purchased out of pocket. Our results show that $14.4 \%$ of the mothers did not vaccinate their girls due to its high cost. The majority of the families included in this study were of the middle class, with a monthly income ranging from 450 USD to 2,000 USD. In Lebanon, the public price of a three-dose course is 210 USD for Cervarix ${ }^{\circledR}$ (GlaxoSmithKline Biologicals, Rixensart, Belgium) and 465 USD for Gardasil $^{\circledR}$ (Merck \& Co., Whitehouse Station, NJ, USA). Thus, this value would render the vaccination unaffordable to most of the population considered in this study. Upon comparing our results to the Moroccan experience, $60 \%$ of the parents did not accept the vaccine because it was very expensive, taking into consideration that the majority came from a low economic class. ${ }^{21}$ Similarly, among Lebanese college students, 49\% of the participants confirmed that the vaccine was unaffordable, despite a minority (14\%) belonging to a middle-low and low economic class. ${ }^{9}$ Even in other wealthy Middle Eastern countries such as the Kingdom of Saudi Arabia, where the price should not constitute an obstacle to vaccine's acceptability, a cross-sectional study involving female students at health colleges in Riyadh responding to a self-administrated questionnaire revealed that $80 \%$ of the participants thought that an affordable price of vaccine should not exceed 80 USD/ vial. ${ }^{28}$ It would be advisable to include adolescent vaccination in the national vaccination program. The government should be able to subsidize HPV vaccines or procure them at a reduced price instead, thus rendering them more affordable to all economic classes.

\section{Limitations and strengths}

The results obtained in this study were limited by a response rate of $39.4 \%$, which might have led to a social desirability bias. Our findings reflected the opinion of families with a limited income leading to another unintentional selection bias. However, this is the first study in Lebanon tackling HPV vaccination awareness among mothers who usually are the decision makers in adolescent vaccination. It also sheds the light on the fact that national vaccination programs should not be limited to pediatric vaccination.

\section{Conclusion}

The level of awareness about HPV vaccine in our studied population was $34.2 \%$. Housewives and participants who were 
married at a young age were not likely to be informed about cervical cancer, HPV, and its vaccine. The reported vaccination rate among vaccine-eligible schoolgirls was low. Barriers to HPV vaccination included the mothers' lack of awareness about cervical cancer and HPV vaccine; the uncertainty among them about the vaccine's safety and efficacy; their conservatism toward their girls' sexual life and denial of its complexity; in addition to the relatively high price of the vaccine and its absence from the national vaccination program.

\section{Availability of data and material}

In addition to the available data in this paper, other data supporting the findings of this study are available from Makassed General Hospital. However, restrictions apply to the availability of these data, which were used under license for the current study, and so are not publicly available. Data are however available from the authors upon reasonable request and with permission of Makassed General Hospital.

\section{Author contributions}

All authors contributed toward data analysis, drafting and critically revising the paper and agree to be accountable for all aspects of the work.

\section{Disclosure}

The authors report no conflicts of interest in this work.

\section{References}

1. GLOBOCAN 2012. Cervical Cancer Incidence and Mortality Worldwide in 2012 Summary. Available from: http://globocan.iarc.fr/old/FactSheets/ cancers/cervix-new.asp. Accessed June 3, 2017.

2. Seoud M, Tjalma WA, Ronsse V. Cervical adenocarcinoma: moving towards better prevention. Vaccine. 2011;29(49):9148-9158.

3. WHO/ICO Information Centre on HPV and Cervical Cancer (HPV Information Centre). Human Papillomavirus and Related Cancers in Lebanon. Summary Report 2010. Available from: http://www.hpvcentre. net/statistics/reports/LBN.pdf. Accessed June 3, 2017.

4. Mroueh AM, Seoud MA, Kaspar HG, Zalloua PA. Prevalence of genital human papillomavirus among Lebanese women. Eur J Gynaecol Oncol. 2002;23:429-432.

5. Bruni L, Barrionuevo-Rosas L, Albero G, et al. ICO Information Centre on HPV and Cancer (HPV Information Centre). Human papillomavirus and related diseases in Lebanon. Summary Report 19 April 2017. Accessed June 3, 2017.

6. World Health Organization. Human papillomavirus vaccines. WHO position paper. Wkly Epidemiol Rec. 2009;84(15):118-131.

7. World Health Organization. Human papillomavirus (HPV). Immunization, Vaccines and Biologicals 2017. Available from: http://www.who. int/immunization/diseases/hpv/en/. Accessed November 3, 2017.

8. Dany M, Chidiac A, Nassar AH. Human papillomavirus vaccination: assessing knowledge, attitudes, and intentions of college female students in Lebanon, a developing country. Vaccine. 2015;33(8):1001-1007.
9. Republic of Lebanon Ministry of Public Health. Expanded Program on Immunization. Available from: https://www.moph.gov.lb/ en/Pages/3/1033/expanded-program-on-immunization/. Accessed November 3, 2017.

10. Jaglarz K, Tomaszewski KA, Kamzol W, Puskulluoglu M, Krzemieniecki K. Creating and field-testing the questionnaire for the assessment of knowledge about cervical cancer and its prevention among schoolgirls and female students. J Gynecol Oncol. 2014;25(2):81-89.

11. Johnson C, Aaronson N, Blazeby JM, et al. EORTC quality of life group. Guidelines for developing questionnaire modules. 4th ed. Brussels: European Organisation for Research and Treatment of Cancer; 2011.

12. Urrutia MT, Hall R. Beliefs about cervical cancer and Pap test: a new Chilean questionnaire. J Nurs Scholarsh. 2013;45(2):126-131.

13. Makwe CC, Anorlu RI, Odeyemi KA. Human papillomavirus (HPV) infection and vaccines: knowledge, attitude and perception among female students at the University of Lagos, Lagos, Nigeria. J Epidemiol Glob Health. 2012;2(4):199-206.

14. Saulle R, Miccoli S, Unim B, et al. Validation of a questionnaire for young women to assess knowledge, attitudes and behaviors towards cervical screening and vaccination against HPV: survey among an Italian sample. Epidemiol Biostat Public Health. 2014;11(2):1-12.

15. Wong LP, Sam IC. Ethnically diverse female university students' knowledge and attitudes toward human papillomavirus (HPV), HPV vaccination and cervical cancer. Eur J Obstet Gynecol Reprod Biol. 2009;148(1):90-95.

16. Chan SS, Yan Ng BH, Lo WK, Cheung TH, Hung Chung TK. Adolescent girls' attitudes on human papillomavirus vaccination. J Pediatr Adolesc Gynecol. 2009;22(2):85-90.

17. Pelucchi C, Esposito S, Galeone C, et al. Knowledge of human papillomavirus infection and its prevention among adolescents and parents in the greater Milan area, Northern Italy. BMC Public Health. 2010; 10(1):378.

18. Marlow LA, Waller J, Wardle J. Parental attitudes to pre-pubertal HPV vaccination. Vaccine. 2007;25(11):1945-1952.

19. "Economy $>$ Population below poverty line: Countries Compared". Available from: http://www.nationmaster.com/country-info/stats/ Economy/Population-below-poverty-line. Accessed June 8, 2017.

20. Ozyer S, Uzunlar O, Ozler S, et al. Awareness of Turkish female adolescents and young women about HPV and their attitudes towards HPV vaccination. Asian Pac J Cancer Prev. 2013;14(8):4877-4881.

21. Mouallif M, Bowyer HL, Festali S, et al. Primary cervical cancer prevention in Morocco: HPV vaccine awareness and acceptability among parents. Procedia Vaccinol. 2014;8:68-76.

22. Marlow LA, Waller J, Evans RE, Wardle J. Predictors of interest in HPV vaccination: a study of British adolescents. Vaccine. 2009;27(18): 2483-2488.

23. Gordon D, Waller J, Marlow LA. Attitudes to HPV vaccination among mothers in the British Jewish community: reasons for accepting or declining the vaccine. Vaccine. 2011;29(43):7350-7356.

24. Nulty DD. The adequacy of response rates to online and paper surveys: what can be done?. Assess Eval High Educ. 2008;33(3):301-314.

25. Hwaid AH. Knowledge and awareness of papillomavirus and cervical cancer among college students and health care workers women in Diyala, Iraq. Am J Public Health Res. 2013;1(8):221-225.

26. Nan X. Relative persuasiveness of gain- versus loss-framed human papillomavirus vaccination messages for the present- and future-minded. Hum Commun Res. 2012;38(1):72-94.

27. Kessels SJ, Marshall HS, Watson M, Braunack-Mayer AJ, Reuzel R, Tooher RL. Factors associated with HPV vaccine uptake in teenage girls: a systematic review. Vaccine. 2012;30(24):3546-3556.

28. Al-Shaikh GK, Almussaed EM, Fayed AA, et al. Knowledge of Saudi female university students regarding cervical cancer and acceptance of the human papilloma virus vaccine. Saudi Med J. 2014;35(10): $1223-1230$. 


\section{Publish your work in this journal}

Therapeutics and Clinical Risk Management is an international, peerreviewed journal of clinical therapeutics and risk management, focusing on concise rapid reporting of clinical studies in all therapeutic areas, outcomes, safety, and programs for the effective, safe, and sustained use of medicines. This journal is indexed on PubMed Central, CAS,

EMBase, Scopus and the Elsevier Bibliographic databases. The manuscript management system is completely online and includes a very quick and fair peer-review system, which is all easy to use. Visit http://www.dovepress.com/testimonials.php to read real quotes from published authors.

Submit your manuscript here: http://www.dovepress.com/therapeutics-and-clinical-risk-management-journal 